\title{
Estimates of Martian crustal thickness from viscous relaxation of topography
}

\author{
F. Nimmo ${ }^{1}$ and D. J. Stevenson \\ California Institute of Technology, Pasadena, California
}

\begin{abstract}
Isostatically compensated crustal thickness variations and associated topographic contrasts at the surface of a planet result in lateral pressure gradients, which may cause the lower crust to flow and reduce the relief. Areas of thicker crust are generally associated with more rapid relaxation of topography. On Mars, topographic features such as impact basins and the hemispheric dichotomy have survived for 4 Gyr. We use a finite difference representation of depth-dependent, non-Newtonian lower crustal flow to investigate how topography decays with time. For a dry diabase rheology, total radiogenic concentrations $\geq 80 \%$ of terrestrial values, and crustal radiogenic concentrations similar to terrestrial basalts, we find that an upper bound on the mean planetary crustal thickness is $\sim 100 \mathrm{~km}$. In the probably unrealistic case where all the radiogenic elements are in the crust, this maximum crustal thickness call be increased to $\sim 115 \mathrm{~km}$. The main uncertainty in these results is the total radiogenic abundances on Mars. Comparing our results with the observed shape of the crustal dichotomy provides no evidence that this slope is primarily the result of lower crustal flow. Both Hellas and the dichotomy are isostatically compensated; if the mechanism is Airy isostasy, then the lower bound on mean crustal thickness is $\sim 30 \mathrm{~km}$. Crustal thicknesses of $30-100 \mathrm{~km}$ on Mars can be produced by mid-ocean ridge spreading at potential temperatures of $1350^{\circ}-1600^{\circ} \mathrm{C}$. However, for such crustal thicknesses the lithosphere is likely to be positively buoyant, making subduction difficult.
\end{abstract}

\section{Introduction}

The crustal thickness on a terrestrial planet such as Mars is a primary indicator of the thermal state, dynamics, and history of the planet. In the absence of seismic data we must rely on less precise, often nonunique indications of crustal thickness and its variation. Here we examine the extent to which we can place bounds on crustal thickness on Mars by appealing to the absence of evidence of relaxation of topographic relief. We focus, in particular, on the crustal dichotomy between the southern highlands and northern plains and on the preservation of large impact basins such as Hellas.

Topographic contrasts at the surface of a planet result in lateral pressure gradients at depth, even when they arise from isostatically compensated crustal thickness variations. On Earth the lower crust in some places is sufficiently ductile to flow over geological time, reducing the topography [e.g., Kruse et al., 1991]. The flow is

\footnotetext{
${ }^{1}$ Also at Bullard Laboratories, Cambridge, England, United Kingdom

Copyright 2001 by the American Geophysical Union.
}

Paper number 2000JE001331.

0148-0227/01/2000JE1331\$09.00 faster if the flowing layer is thicker or less viscous. Because large, isostatically compensated topographic contrasts on Mars have survived for about $4 \mathrm{Gyr}$, lower crustal flow must not have been important over this time period. We use estimates of the temperature structure and rheology of the ancient Martian crust to demonstrate that the crustal thickness of the southern highlands is unlikely to have exceeded $125 \mathrm{~km}$ and is more probably $<100 \mathrm{~km}$. Assuming that topographic features such as the Hellas and Argyre impact basins are supported by Airy isostasy, the crustal thickness of the southern highlands cannot be less than $\sim 40 \mathrm{~km}$.

Zuber et al. [2000] considered a similar problem, using a viscoelastic rheology with surface layers which were effectively elastic. These authors considered the decay of the long wavelength $(l=1)$ component of the crustal dichotomy and concluded that the existence of the dichotomy was consistent with mean crustal thicknesses of $50 \mathrm{~km}$ but not $100 \mathrm{~km}$. Our model uses a different depth-dependent viscosity structure and does not consider elastic support but reaches a similar conclusion.

Section 2 outlines a simple theory describing lower crustal flow. Section 3 describes the observations of topographic contrasts on Mars, and section 4 demonstrates the application of the theory to two specific ex- 
amples. Section 5 discusses the uncertainties in the resulting bounds on crustal thickness and implications of the results.

\section{Theory}

Models of lower crustal flow liave been used to investigate the relaxation of topography in various settings on Earth [e.g., Mckenzze ef al., 2000; Bott, 1999; Zhong, 1997: Burd, 1991; Fusznir and Matthews, 1988]. Similar ideas liave also been applied to bodies such as Venus [Grımm and Solomon, 1988; Bındschadler and Parmentier, 1990], Ganymede [Hillgren and Melosh, 1989], and Europa [Ojakangas and Stevenson, 1989; Thomas and Schubert, 1986]. Most models [e.g., McKenzie et al., 2000; Zhong, 1997; Nakada, 1994; Kusznir and Matthews, 1988] show that the timescale for reducing lateral crustal thickness contrasts due to lower crustal flow $\left(\tau_{1}\right)$ is always much longer than the timescale for attaining local isostatic equilibrium through vertical motions of crust and mantle $\left(\tau_{2}\right)$. In the simple case of an isoviscous half-space, $\tau_{2} \sim \eta_{m} / \rho_{m} g \lambda$, where $\eta_{m}$ is the mantle viscosity, $\rho_{m}$ is the mantle density, $g$ is the gravitational acceleration and $\lambda$ is the wavelength of the disturbance. Even though $\eta_{m}$ may be considerably larger than the viscosity of the lowermost crust, this timescale is typically comparable to postglacial rebound timescales ( $\sim 10^{4}$ years) and unlikely to exceed $\sim 10^{6}$ years, especially at early epochs, even for the shortest wavelengths that we consider here. Furthermore, $\tau_{2}$ tends to decrease with increasing wavelength, whereas $\tau_{1}$, in general, increases (but see Zhong [1997]).

Horizontal flow in the lower crust is driven by lateral pressure gradients (see Figure 1). Assuming that vertical flow is negligihle and that effects such as convection withn the lower crust are not important, we have

$$
0=-\frac{\partial P}{\partial x}+\frac{\partial \tau_{x z}}{\partial z}
$$

where $P$ is pressure and $\tau_{x z}$ is horizontal shear stress. For an isostatically compensated crust the lateral pressure gradient is related to lateral topography gradients:

$$
\frac{\partial P}{\partial x}=\Delta \rho g \frac{\partial D}{d x}
$$

where $D(x)$ is the crustal thickness, $g$ is gravity, and $\Delta \rho$ is the density contrast between crust and mantle.

For a non-Newtonian material, the relationship between shear stress and strain rate is as follows:

$$
\dot{\epsilon}=\frac{\partial v}{\partial z}=A\left|\tau_{x z}\right|^{n-1} \tau_{x z} e^{-Q / R T},
$$

where $\dot{f}$ is strain rate, $v$ is horizontal velocity, $A, Q$, and $n$ are rheological parameters, and $T$ is absolute temperature.

Integration of (1) yields the shear stress; use of (2) and (3) then yields the horizontal velocity:

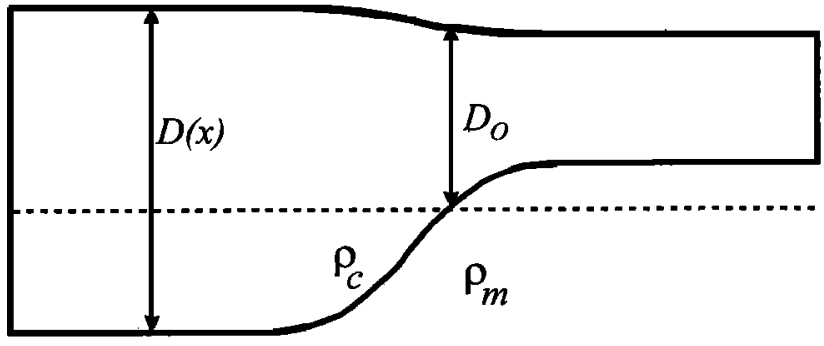

Figure 1. Sketch of isostatically balanced crustal section in which lower crustal flow may occur. Average crustal thickness is $D_{0}$.

$$
\begin{aligned}
v(z)= & \int_{0}^{z} A\left|\Delta \rho g \frac{\partial D}{\partial x} z^{\prime}-\tau_{0}\right|^{n-1} \\
& \left(\Delta \rho g \frac{\partial D}{\partial x} z^{\prime}-\tau_{0}\right) e^{-Q / R T} d z^{\prime}
\end{aligned}
$$

where $\tau_{0}$ is an undetermined constant of integration.

In order to relate the exponential term to the crustal thermal structure (see equations (11)-(14) below) we linearize as follows:

$$
\exp (-Q / R T) \approx E_{b} \exp (-z / \delta)
$$

for small $z$, where $\delta$ is a characteristic lengthscale, $E_{b}=$ $\exp \left(-Q / R T_{b}\right)$, and $T_{b}$ is the temperature at the base of the crust. Note that it is not necessary for $T$ to be linear with $z$ to make this approximation.

Equation (4) nay be rewritten as

$$
v(z)=F \int_{0}^{z}\left|z^{\prime}-\alpha\right|^{n-1}\left(z^{\prime}-\alpha\right) e^{-\dot{z}^{\prime} / \delta} d z^{\prime},
$$

where $F=A E_{b}(\Delta \rho g \partial D / \partial x)^{n}$ and $\alpha^{-1}=\frac{\partial D}{\partial x} \Delta \rho g / \tau_{0}$. The constant $\alpha$ is found from the requirement that $v(D)=0$. Obviously, $\alpha$ is of order $\delta$.

Conservation of mass gives the equation of continuity in two dimensions,

$$
\frac{d D}{d t}=-\frac{d}{d x} \int_{0}^{D} v d z
$$

and for an axisymmetric case,

$$
\frac{d D}{d t}=-\frac{1}{r} \frac{d}{d r}\left(r \int_{0}^{D} v d z\right)
$$

Having obtained $a$, we use continuity to obtain the rate of change of crust.al thickness:

$$
\frac{d D}{d t}=-\frac{d}{d x} A E_{b}\left|\Delta \rho g \frac{\partial D}{\partial x}\right|^{n-1} \Delta \rho g \frac{\partial D}{\partial x} B,
$$

where

$$
B=\int_{0}^{D} \int_{0}^{z}\left|z^{\prime}-\alpha\right|^{n-1}\left(z^{\prime}-\alpha\right) e^{-z^{\prime} / \delta} d z^{\prime} d z
$$


In the Newtonian limit $(n=1)$, (9) reduces to the standard diffusion equation for the evolution of $D$, but with an effective diffusivity that is spatially variable. This variability arises primarily because $E_{b}$ is a (strong) function of $T_{b}$, which is, in turn, a (weak) function of location, $x$. The parameter $B$ is also $x$ dependent. Consequently, it is usually inappropriate to employ a model analysis using either Fourier components or spherical harmonics, since they will not decouple. For example, a spherical harmonic of a particular $l$ value (e.g., $l=1$, the "crustal dichotomy") will evolve in a way that is no longer represented by a single harmonic. Accordingly, we regard the spatial description employed here as superior to a relaxation time (modal) analysis. This is even more strikingly evident when $n \neq 1$ and (9) becomes strongly nonlinear. Indeed, the form of the equation shows that consideration of wavelengths much smaller than $R$, the planetary radius, is essential and accordingly the use of a local Cartesian analysis is appropriate.

The temperature at the base of the crust, $T_{b}$, depends on the thermal structure of the crust. This structure is governed by crustal radiogenic heat production and mantle heat flow. Crustal materials on Earth are typically enriched in radiogenic elements relative to the bulk mantle concentration by a factor $p$ where $p \approx 4$ for mid-ocean ridge basalts (MORBs) and up to 150 for the upper continental crust [Taylor and McLennan, 1985]. The value of $p$ depends on the specific mode of crustal formation, which for Mars is unknown, and we thus treat $p$ as a free parameter. However, we note that for a single-stage melting process, $p$ will vary approximately as the inverse of the melt fraction.

Let the bulk concentration of radiogenic elements in undepleted (i.e., prior to extraction of the crust) terrestrial mantle as a function of time be $c_{0}(t)$ and the ratio of concentrations in the undepleted mantle of Mars to that of Earth be $C$. If the volume of the Martian crust is $V_{c}$ and that of the mantle remaining after crustal formation is $V_{m}$, then the concentration of radiogenic elements remaining in the mantle, $c_{m}(t)$, is given by

$$
c_{m}(t)=C c_{0}(t)\left(1+\frac{V_{c}[1-p]}{V_{m}}\right)
$$

for $p<1+\left(V_{m} / V_{c}\right)$. The crustal heat production $H$ can then be calculated if the initial abundances and decay times of the various radiogenic elements are known, assuming a uniform distribution of heat-producing elements within the crust. The mantle heat flux $F_{0}$ is found by assuming that the heat flux out of the mantle is balanced by the radiogenic heat production, i.e., it ignores any contribution from the core or from secular cooling. In section 5 we argue that this assumption is probably justified for small planets with single-layer mantles such as Mars. Secular cooling would increase the mantle heat flux and thus reduce the maximum permissible crustal thickness. Another complication is that there may be lateral variations in mantle heat flux, due to variations in lithospheric thickness or mantle convection. We do not consider such variations in this work.

It should be noted that $p$ and $V_{c} / V_{m}$ are not truly independent variables: for a single-stage melting process they tend to be anticorrelated, since high $p$ values arise from small melt fractions, which favor low crustal thicknesses. The high values of $p$ for continental materials and reasonably high crustal thicknesses $(\sim 35 \mathrm{~km})$ probably occur because crustal assembly involved a multistage melting process, including contributions from both high and low melt fractions [O'Nıons and Mclienzıe, 1988]. Since we are treating $p$ and $V_{c} / V_{m}$ as independent variables, the details of the melt generation process are not addressed. However, the crust cannot contain more radiogenic materials than were originally present in the undepleted mantle.

The increase in temperature with depth depends on the distribution of radiogenic elements with depth. Consider a crustal layer of thickness $t_{c}$ in which the radiogenic elements are uniformly distributed, producing a heat generation rate of $H$. The heat flux into the base of the crust is $F_{0}$, and the surface temperature is $T_{s}$. Setting the vertical axis $z=0$ at the base of the crust, the temperature $T$ as a function of $z$ is

$$
T(z)=T_{s}+\frac{F_{0}}{k}\left(t_{c}-z\right)+\frac{H}{2 k}\left(t_{c}^{2}-z^{2}\right),
$$

where $k$ is the conductivity.

If the temperature at the base of the crust $(z=0)$ is $T_{b},(12)$ may be restated as

$$
T(z)=T_{b}-\frac{F_{0} z}{k}-\frac{H z^{2}}{2 k} .
$$

Figure 2a shows a typical Martian temperature profile at $4 \mathrm{Ga}$ before present (B.P.) using (13) and assuming $p=4$ and $C=0.9$. In this particular example the temperature profile is nearly linear because crustal heat production is much smaller than the total mantle heat production.

Comparison with (5) shows that

$$
\delta=\frac{R k T_{b}^{2}}{Q F_{0}}
$$

This relationship is exact at $z=0$; at shallower depths the approximation (equation (5)) understates the value of $\exp (-Q / R T)$. Figure $2 \mathrm{~b}$ shows that most of the flow occurs within a layer of thickness a few times $\delta$; over this distance the error in (5) is small. Figure $2 b$ also shows that as $n$ increases, the flow becomes more pluglike with narrow shear zones at the boundaries. This effect is typical of non-Newtonian flows [e.g., Turcotte and Schubert, 1982].

\section{Observations}

The composition, thickness, and age of formation of the Martian crust are not well known. SNC meteorites 

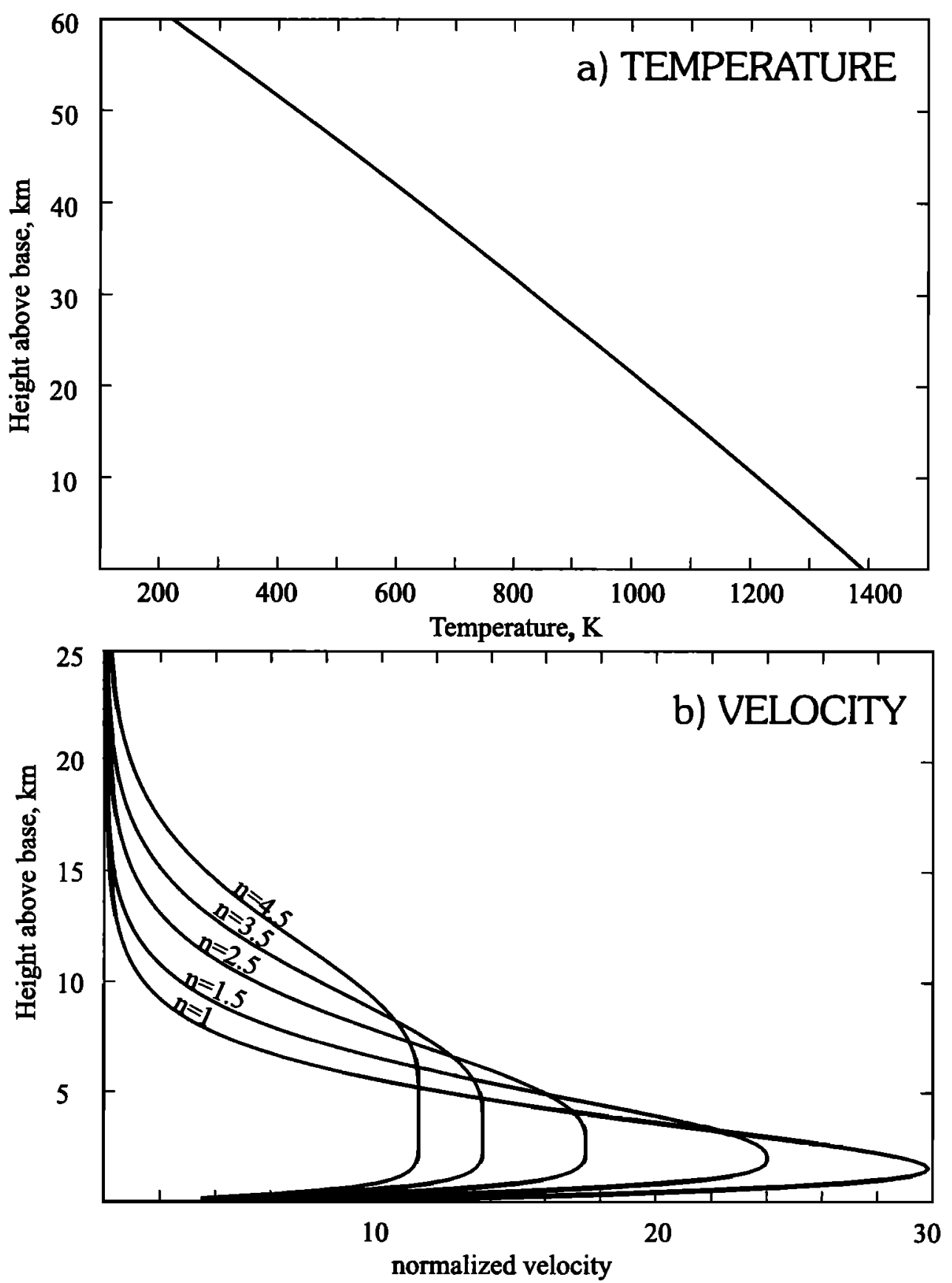

Figure 2. Variation of parameters with depth in $60 \mathrm{~km}$ thick crust for model Mars at $4 \mathrm{Ga}$ B.P. (a) Temperature (in K). Crustal enrichment factor $p=4, C=0.9$, resulting in a mantle heat flux of $50.3 \mathrm{~mW} \mathrm{~m}^{-2}$ and a crustal heat production of rate of $0.198 \mu \mathrm{W} \mathrm{m}^{-3} ; \delta$ is $1.7 \mathrm{~km}$ (see equation (14)). (b) Dimensionless horizontal velocity (normalized to mean horizontal velocity), assuming dry diabase rheology (see Table 1) but varying the value of $n$. The mean horizontal velocity is small because it is taken over the $60 \mathrm{~km}$ crustal thickness.

suggest that it may be basaltic [e.g., McSween, 1994], but the Mars Pathfinder mission found potassium concentrations of $0.7 \pm 0.2 \mathrm{wt \%}$, compared with typical basaltic values of 0.1-0.2 wt\% [McSween et al., 1999]. The bulk composition of the Martian mantle is probably rather more iron rich than that of Earth but otherwise similar ([Longhi et al., 1992]. The iron-rich nature of the mantle means that it may be denser than that of terrestrial mantle material. In this work, mantle density $\rho_{m}$ was assumed to be $3400 \mathrm{~kg} \mathrm{~m}^{-3}$, and crustal density $\rho_{c}$ was assumed to be $2900 \mathrm{~kg} \mathrm{~m}^{-3}$.

Previous crustal thickness estimates have mainly relied on gravity and topography data or models based on SNC compositions. Zuber et al. [2000] used gravity and topography to place a lower bound on the crustal thickness of $\sim 50 \mathrm{~km}$ and argued that a crustal thickness of 
Table 1. Values of Constants Used in Calculations.

\begin{tabular}{llrr}
\hline Quantity & Symbol & Value & Units \\
\hline Surface gravity & $g$ & 3.72 & $\mathrm{~m} \mathrm{~s}^{-2}$ \\
Density contrast & $\Delta \rho$ & 500 & $\mathrm{~kg} \mathrm{~m}^{-3}$ \\
Surface temperature & $T_{s}$ & 220 & $\mathrm{~K}$ \\
Crustal enrichment factor & $p$ & 4 & - \\
Mantle enrichment factor & $C$ & 0.9 & - \\
Thermal conductivity & $k$ & 3.2 & $\mathrm{~W} \mathrm{~m}^{-1} \mathrm{~K}^{-1}$ \\
Dry diabase & $A$ & $4.9 \times 10^{3}$ & $\mathrm{M} \mathrm{Pa}^{-\mathbf{n}}$ \\
& $n$ & 4.5 & - \\
& $Q$ & 500 & $\mathrm{~kJ} \mathrm{~mol}^{-1}$ \\
\hline
\end{tabular}

$100 \mathrm{~km}$ was incompatible with the survival of the longwavelength crustal dichotomy. Sohl and Spohn [1997] used SNC compositions and the assumption of chondritic abundances to estimate a basaltic crustal thickness of $100-250 \mathrm{~km}$, but this value is suspect because Mars appears not to be chondritic [Bertka and Fei, 1998]. Norman [1999] used rare earth element abundances in SNC meteorites to estimate a global average crustal thickness of $<45 \mathrm{~km}$. Bills and Ferrari [1978] obtained a mean crustal thickness of 24-32 km from low order gravity and topography, assuming zero thickness crust beneath Hellas. Sjogren and Wimberley [1981], by contrast, estimated the depth of compensation beneath Hellas to be $100-160 \mathrm{~km}$. Kiefer et al. [1996] found that they could not distinguish between crustal thicknesses of $25 \mathrm{~km}$ and $100 \mathrm{~km}$ using low-order gravity and topography. The thickness of crust produced at a mid-ocean ridge $(\sim 7 \mathrm{~km}$ on Earth) will scale inversely with the gravity of the planet for constant mantle temperature [McKenzle and Brckle, 1988].

In this study the concentration of radiogenic elements in the primitive mantle of Mars was assumed to be a factor of $C$ times the terrestrial concentration values of Sun and McDonough [1989]. We generally assumed $C$ to be 0.9 , which produces heat fluxes at $4 \mathrm{Gyr}$ B.P. similar to those from published models for Mars [e.g., Wanke and Dreibus, 1988; Laul et al., 1986], although we note that some models produce lower heat fluxes [e.g., Treiman et al., 1986] and the total uncertainty is perhaps a factor of 2 [Schubert et al., 1992]. The effect of the radiogenic abundance assumed is examined in section 5. The rheology of the Martian crust depends on its composition. We generally assumed the material to be dry diabase [Mackwell et al., 1995], since this is the stiffest of the likely crustal materials. The core radius was assumed to be $1450 \mathrm{~km}$ [Folkner et al., 1997] and Table 1 gives the value of other constants used.

Measurements of isotopic ratios in SNC meteorites suggest that the Martian crust formed within a few hundred Myr after $4.5 \mathrm{Ga}$ B.P. [Blichert-Toft et al., 1999; Borg et al, 1997], with insignificant subsequent crustal recycling, at least of the near-surface crust that the SNCs most probably represent. The southern highlands, which form $60 \%$ of the surface of the planet, are Noachian in age (i.e., older than $3.5 \mathrm{Ga}$ ) [Tanaka et al., 1992]. Since the early Noachian $(4.5-3.9 \mathrm{Ga})$, the total volume of volcanism has been estimated as equivalent to a global layer only $4.5 \mathrm{~km}$ thick [Greeley and Schnerd, 1991]. Of course, these geological estimates cannot constrain intrusive activity accurately. Nevertheless, it seems likely that by $\sim 4 \mathrm{Ga}$ B.P. the main bulk of the Martian crust had formed.

Results from Mars Global Surveyor (MGS) [Smith et al, , 1999a] show that Mars exhibits considerable relief at various lengthscales. The southern hemisphere has a higher average elevation than the northern hemisphere, well represented as a step of $2-4 \mathrm{~km}$ over a few hundred kilometers [Frey et al., 1998]. The age of origin of this dichotomy is not certain. However, it probably predates the early Hesperian, so it must be at least 3.5-3.8 Gyr old [Tanaka et al., 1992; McGill and Dimitriou, 1990]. Figure 3a shows the topography of a series of N-S profiles across the crustal dichotomy. Figure 3 b shows the observed gravity (to $l=m=50$ ) compared with the gravity that would be observed if the dichotomy were rigidly supported. At wavelengths of around $400 \mathrm{~km}$ the amplitudes of the observed gravity anomalies at the dichotomy are of order $30 \%$ of those predicted for a rigidly supported load. An elastic layer of thickness $10 \mathrm{~km}$ would produce anomalies of $\sim 50 \%$ of a rigidly supported load at these wavelengths. Thus the dichotomy is essentially isostatically supported. This conclusion agrees with previous authors [Smith et al., 1999b; Phillips, 1988; Janle, 1983].

The largest impact basin on Mars is Hellas, some $2300 \mathrm{~km}$ in diameter and $8 \mathrm{~km}$ deep [Smith et al., $1999 \mathrm{a}$ ]. It is probably Noachian in age [Tanaka et al., 1992], suggesting that it formed within the first $0.5 \mathrm{Gyr}$ of Mars' history. As with the crustal dichotomy, Hellas appears to be essentially isostatically supported [Smith et al., 1999b], as does the similarly sized South PoleAitken basin on the Moon [Neumann et al., 1996].

The important conclusion is that there exist large topographic contrasts which are mainly isostatically supported and which have survived for $\sim 4 \mathrm{Gyr}$. The isostatic nature of the topography is important because it allows us to ignore elastic effects. Below, we use these observations to constrain the maximum likely crustal thickness at $4 \mathrm{Ga}$ B.P. 

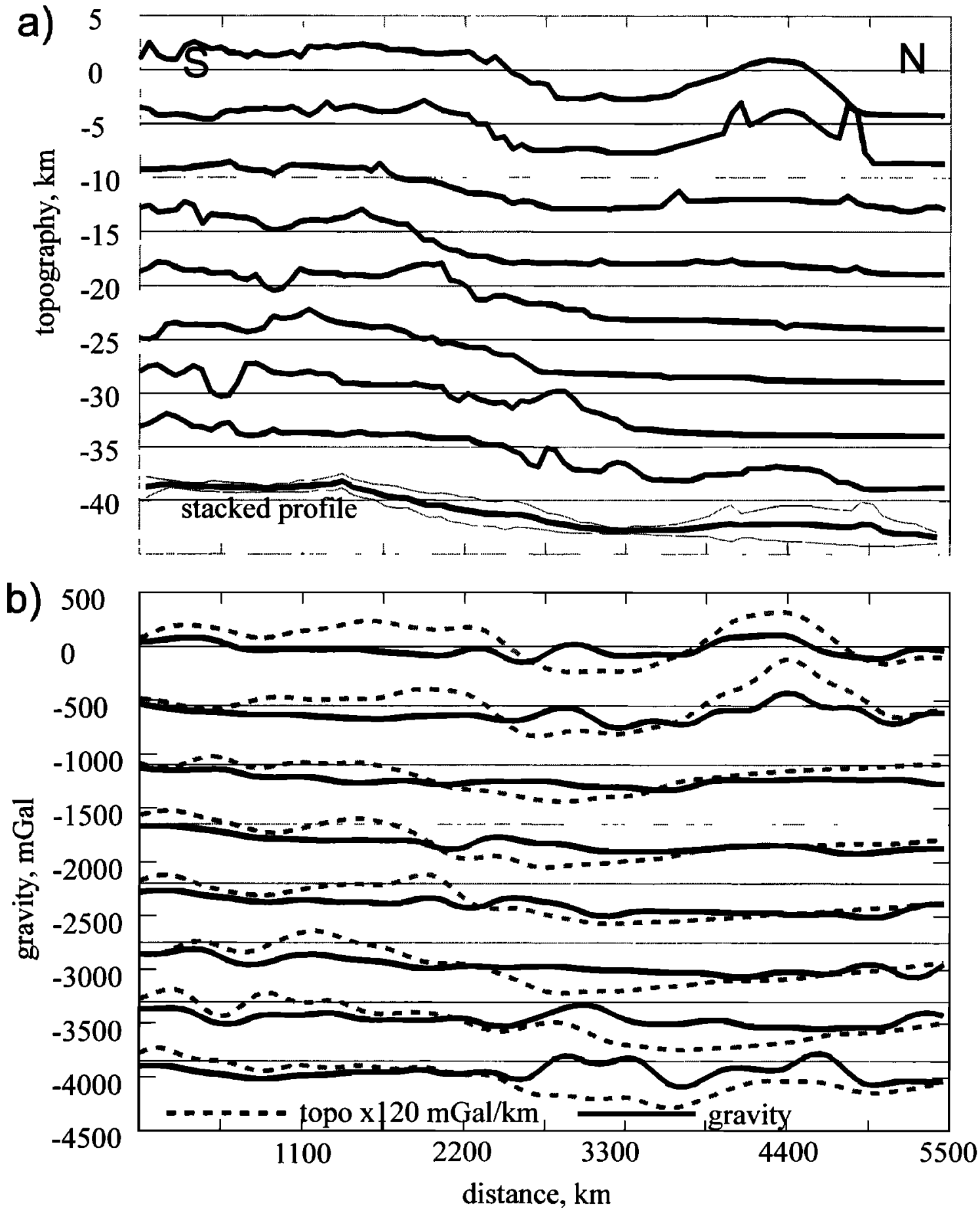

Figure 3. Crustal dichotomy topography and gravity. (a) Solid lines are N-S profiles st.arting from $50^{\circ} \mathrm{S}$. spaced at intervals of $10.55^{\circ}$ east.ward from $220^{\circ} \mathrm{W}$. Limes were generated by interpolating at $60 \mathrm{~km}$ intervals from $0.5^{\circ} \times 0.5^{\circ}$ gridded topography [Simuth et al., 1999a] and each is offset vertically by $5 \mathrm{~km}$ for clarity. The profile at the bottom is the mean of the stacked profiles. Stacking was accomplished by aligning the maximum slopes of a smoothed version of each profile. Smoothing used a $1500 \mathrm{~km}$ wide moving average. Thinner lines above and below are $+/$ - one standard deviation. (b) Solicl lines are gravity calculated from spherical harmonic model jgni75c01 [Smith et al., 1999b] up to degree and order 50 for the same locations as in Figure 3a. Vertical offset is $550 \mathrm{mGal}$ for successsive profiles. Dotted lines are spherical harmonic topography calculated from degree and order 2 to 50 and multiplied by a factor of $120 \mathrm{mGal} \mathrm{km}^{-1}$ to show the gravity anomaly that would be seen if the topography were rigidly supported. Spherical harmonics were generated from the gridded topography used in Figure $3 \mathrm{a}$. 


\section{Calculations}

Equation (9) shows that a thicker crust will be hotter and flow will thus proceed more rapidly. Areas with steeper slopes also tend to decay more rapidly. The equation does not incorporate lateral temperature variations or time-varying heat flux, both of which may be important. To take into account these complications, we used a finite difference version of (9) to calculate the evolution of topography with time. The initial crustal thickness $D(x)$ was calculated from the observed topography by assuming isostasy and an average crustal thickness $D_{0}$. Lateral variations in basal temperature were incorporated by assuming that $T_{b}$ varied as

$$
T_{b}(x)=T_{b 0}+\left[D(x)-D_{0}\right]\left(T_{b 0}-T_{s}\right) / D_{0},
$$

where $T_{b 0}$ is the value of $T_{b}$ at $D=D_{0}$. This approximation works best when the heat flow is predominantly from the mantle (as in Figure 2a).

The temperature profile in the crust was calculated using (11) and (13). Because relaxation occurs most rapidly early on, we used a variable time step such that the change in $D$ from one time step to the next never exceeded $100 \mathrm{~m}$. At each time step we updated the values of $F_{0}$ and $T_{b}$ according to the decay of radiogenic elements with time and recalculated the values of $\delta$ and $\alpha$. Equations (6) and (10) were integrated numerically; we checked the calculations by using integer $n$, for which the integrations may be obtained analytically. The horizontal spacing was $50 \mathrm{~km}$, and the boundary conditions were reflecting. Below, we apply this model to two specific examples.

\subsection{Hemispheric Dichotomy}

The origin of the hemispheric dichotomy is unknown. It is conceivable that the elevation difference is due to compositional differences between north and south. Although no landers have yet measured the composition of rocks in the southern highlands, the Pathfinder results did suggest that more felsic compositions might exist in addition to basalts [McSween et al., 1999]. For a crustal thickness of $40 \mathrm{~km}$ a $3 \mathrm{~km}$ elevation difference would require a density contrast of $200 \mathrm{~kg} \mathrm{~m}^{-3}$, which is larger than typical density contrasts between continental and oceanic material on Earth. It may be that the north is low because of a combination of higher density and smaller thickness, as occurs with oceanic crust on Earth. However, infrared spectra from MGS suggest that the northern lowlands are if anything more silicic (and hence less dense) than the southern highlands [Bandfield et al., 2000]. Accordingly, it will be assumed that the hemispheric dichotomy is supported by Airy isostasy. In this case the $2-4 \mathrm{~km}$ step [Frey et al., 1998] represents a crustal thickness contrast of 14$28 \mathrm{~km}$ for the clensities assumed in this study [see also Janle, 1983]. These values provide a lower bound on the thickness of the southern crust.
Figure 3a shows an average topographic profile of the dichotomy, obtained by stacking the eight plotted profiles. The maximum slope of this profile is 0.003 and 0.008 after smoothing by a moving average of $1500 \mathrm{~km}$ and $300 \mathrm{~km}$ width, respectively. Locally slopes may be steeper, but would decay more rapidly according to (9). In reality, such short-wavelength features are likely to be elastically supported, but as we argue below, elastic support does not appear to be important at the wavelengths of interest.

The shape of the profile at $4 \mathrm{Ga}$ B.P. is unknown; here we assume that it was similar to the present day, but with a steeper slope. For simplicity, we take the initial shape to be an inverse tangent profile of topographic step $3 \mathrm{~km}$ superimposed on a regional slope of $1 \mathrm{~km} / 400 \mathrm{~km}$ (Figure 4). The maximum initial slope of the profile is 0.022 if the half width is $50 \mathrm{~km}$. The exact value of the initial slope is not important as long as it exceeds the present-day value.

Figures $4 \mathrm{a}-4 \mathrm{~d}$ show the evolution of this model topography with time, starting from 4 Ga B.P. and using the finite difference technique outlined above. As expected from (9), a thicker crust causes much greater topographic relaxation. The present-day shape of the dichotomy is not well matched by crustal thicknesses of $90 \mathrm{~km}$ or more. For a model in which $D_{0}=90 \mathrm{~km}$, at $4 \mathrm{Ga}$ B.P. the mantle heat flux (after crustal extraction) is $45 \mathrm{~mW} \mathrm{~m} \mathrm{~m}^{-2}$ and $\delta$ is $3.6 \mathrm{~km}$. Mainly because of the decrease in slope with time, most of the topographic evolution takes place within the first $10 \mathrm{Myr}$. Note that there is a tendency for steep slopes to develop at the edge of the low topography, because this area is thinned and cold and flow rates are therefore slower.

One way of illustrating the decay of the model topography is to track the slope as a function of time. Figure 5a summarizes the change in slope at the halfway point with time for the different models. The dashed lines show the present-day maximum slope of the stacked profile after smoothing and demonstrate that average crustal thicknesses of greater than $\sim 90 \mathrm{~km}$ cannot maintain such slopes over $4 \mathrm{Gyr}$, as was also concluded from Figure 4. This mean thickness implies the maximum southern crustal thickness is $\sim 100 \mathrm{~km}$.

Figure 5b shows the effect of varying other parameters in the model. Increasing the total radiogenic abundance or decreasing the crustal concentration reduces topographic contrasts more rapidly, because $T_{b}$ increases. The initial slope (not shown) has very little effect, which is to be expected since shorter-wavelength features decay more rapidly. Decreasing the total radiogenic abundance or increasing the crustal concentration factor $p$ increases the maximum permitted crustal thickness substantially, because of the exponential dependence on $T_{b}$.

Figure 6 shows the dependence of lower crustal flow timescales on total radiogenic abundances and crustal concentrations. The relaxation time is defined as the time taken for the initial maximum slope to reduce 

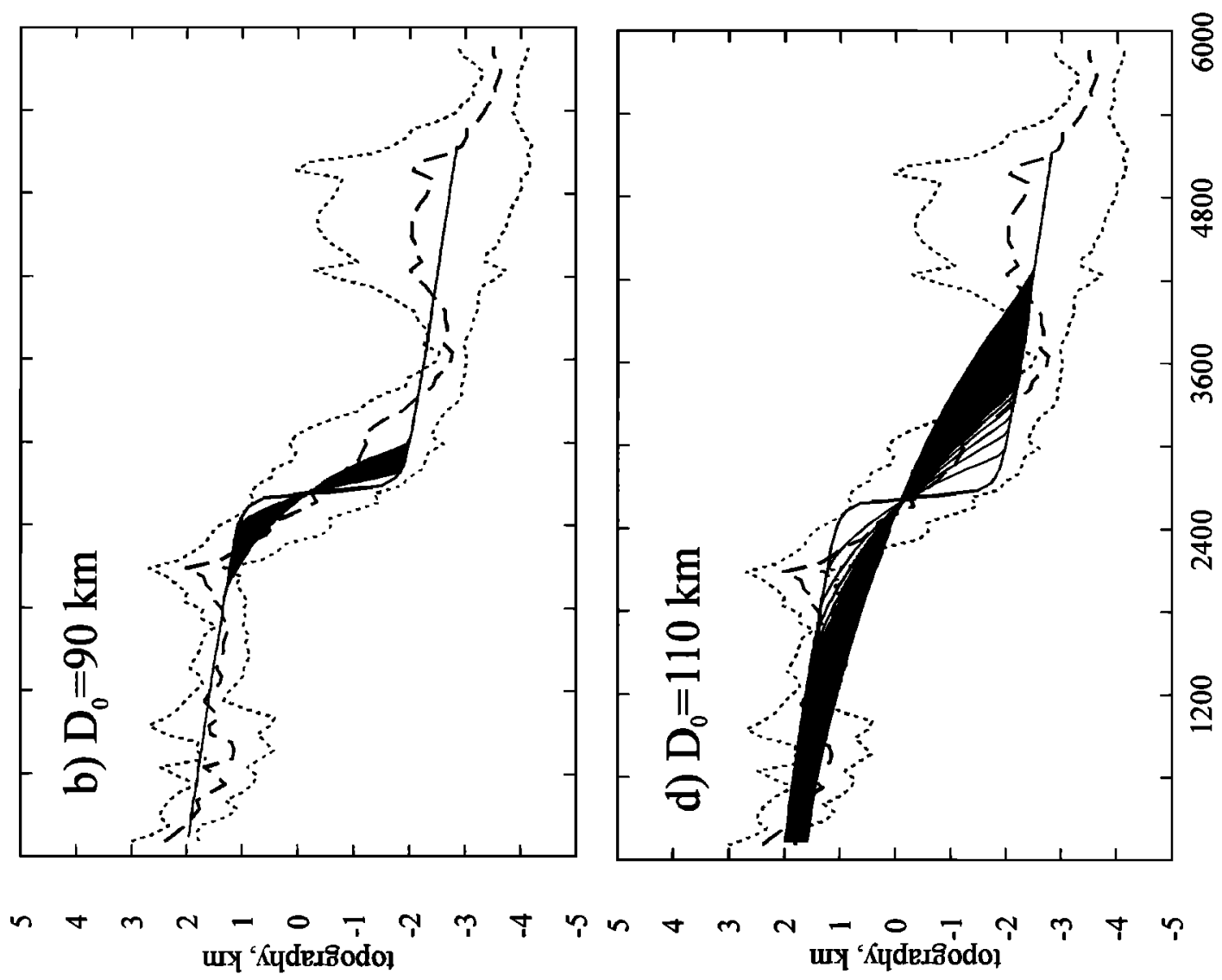

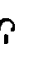

\&े

8̊

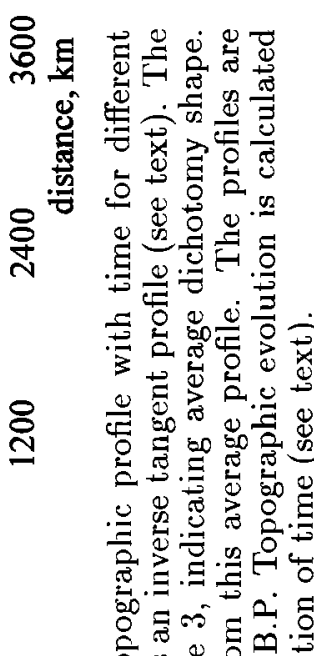

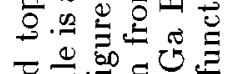

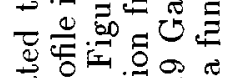

$8 \quad 0 \quad 000$
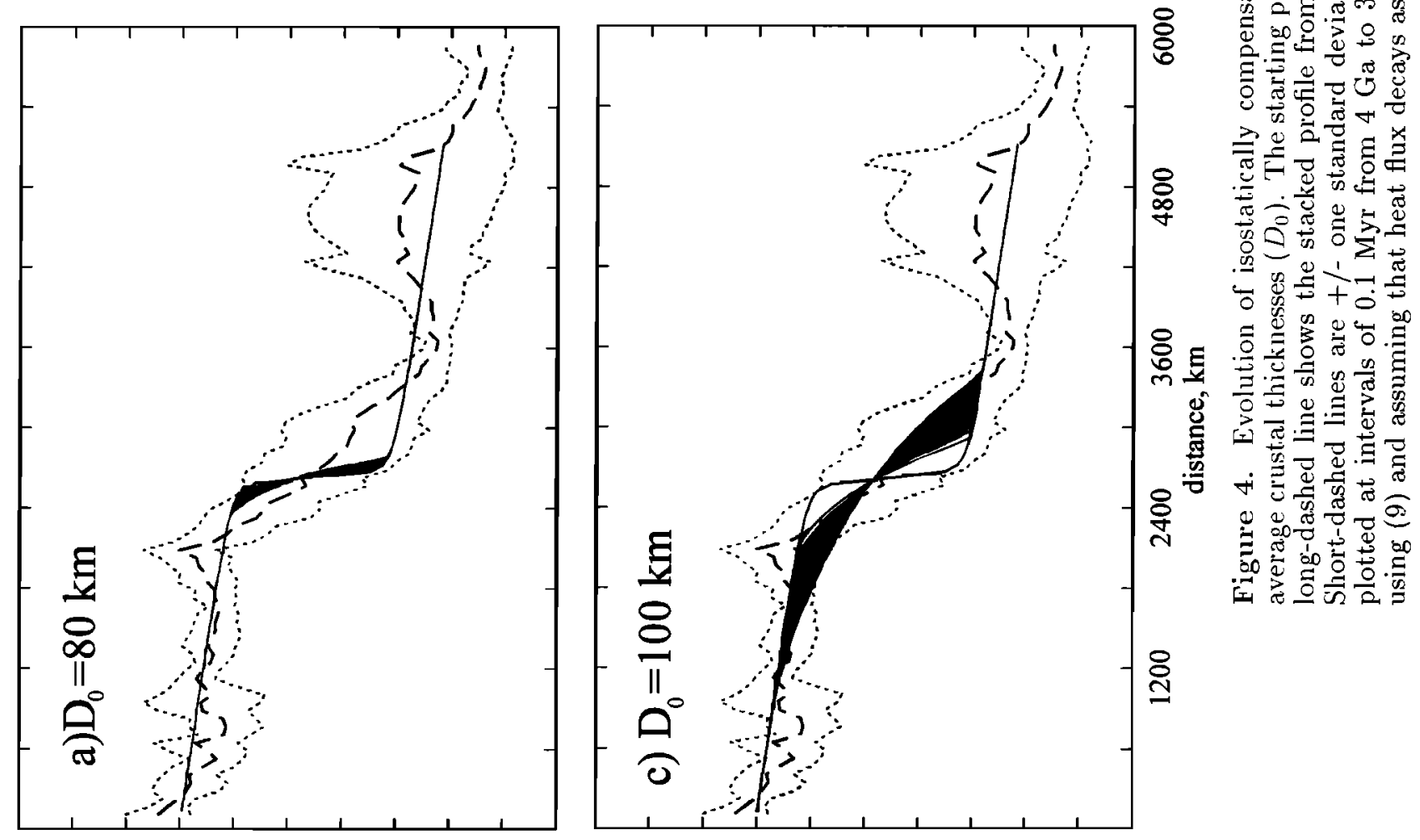

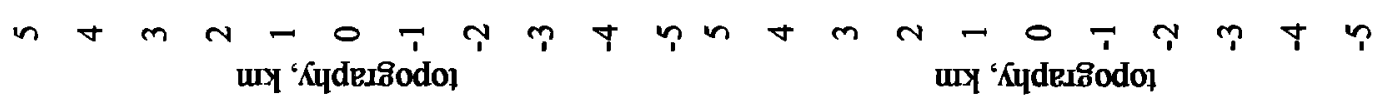



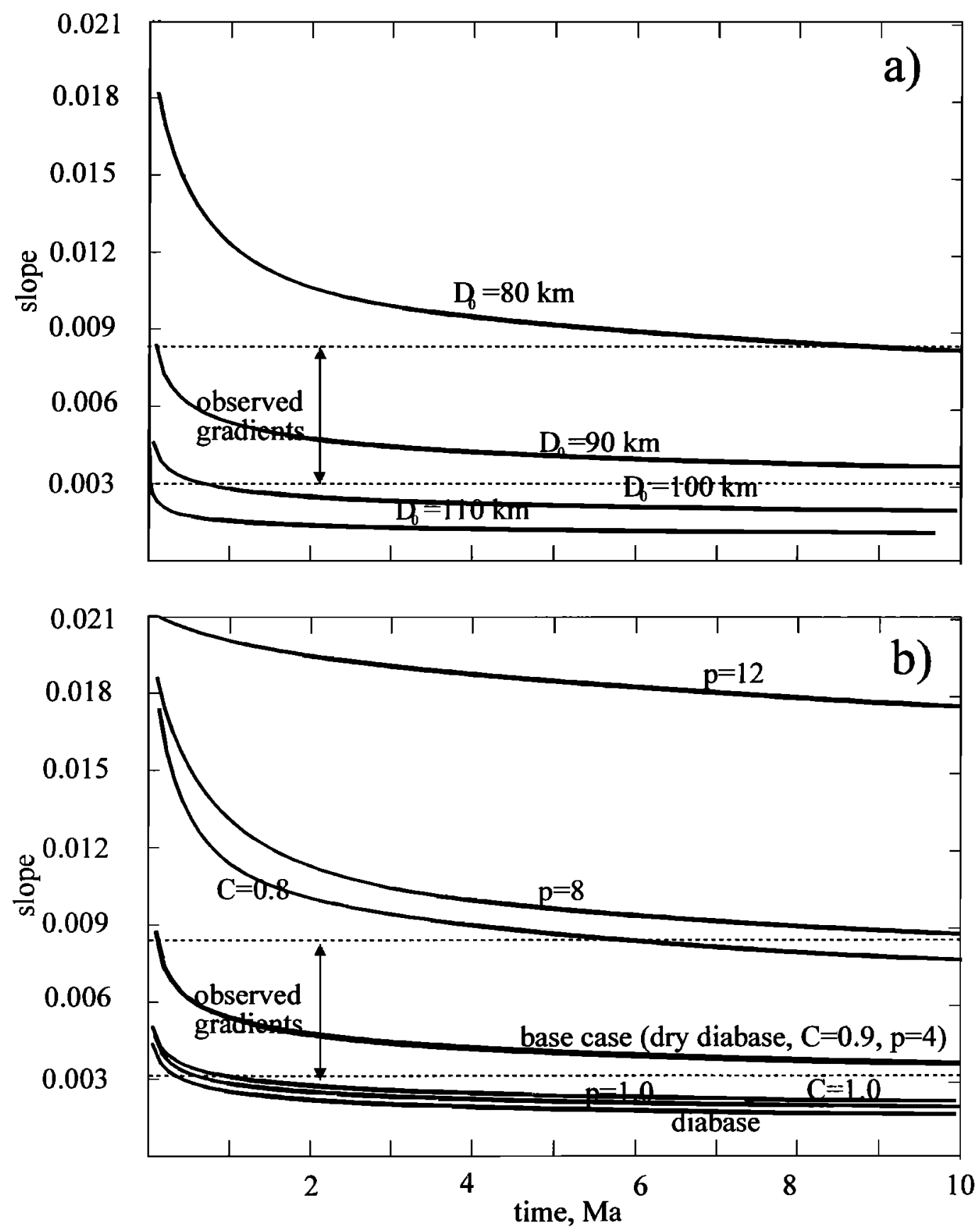

Figure 5. Evolution of maximum topographic slope of crustal dichotomy with time. (a) Solid lines show model slope evolution for different average crustal thicknesses $\left(D_{0}\right)$ and starting conditions discussed in text and shown in Table 1. The crustal concentration factor $p=4$ and $C=0.9$. Dashed lines represent present-day maximum slope of the stacked profile (see Figure 3a) calculated using a moving average of $300 \mathrm{~km}$ and $1500 \mathrm{~km}$ width. (b) Effect of varying parameters on slope evolution. The bold line shows the base case with $D_{0}=90 \mathrm{~km}$ and other initial parameters from Table 1. Solid lines show the effect of varying rheology, crustal concentration factor $p$ and radiogenic concentrations relative to Earth $(C)$. Diabase rheology is from Shelton and Tullss [1981].

from its starting value to 0.003 , the minimum regional slope of the present-day dichotomy. Figure 6 shows that the relaxation time decreases as the crustal thickness increases or the crustal concentration factor decreases. Increasing the total radiogenic abundance decreases all relaxation timescales. The relaxation time is extremely sensitive to crustal thickness because increasing the crustal thickness increases $T_{b}$, which both increases $\delta$ (a relatively small effect) and reduces the effective viscosity (a large effect).

The relaxation time increases superexponentially as crustal thickness decreases, because the relaxation time 


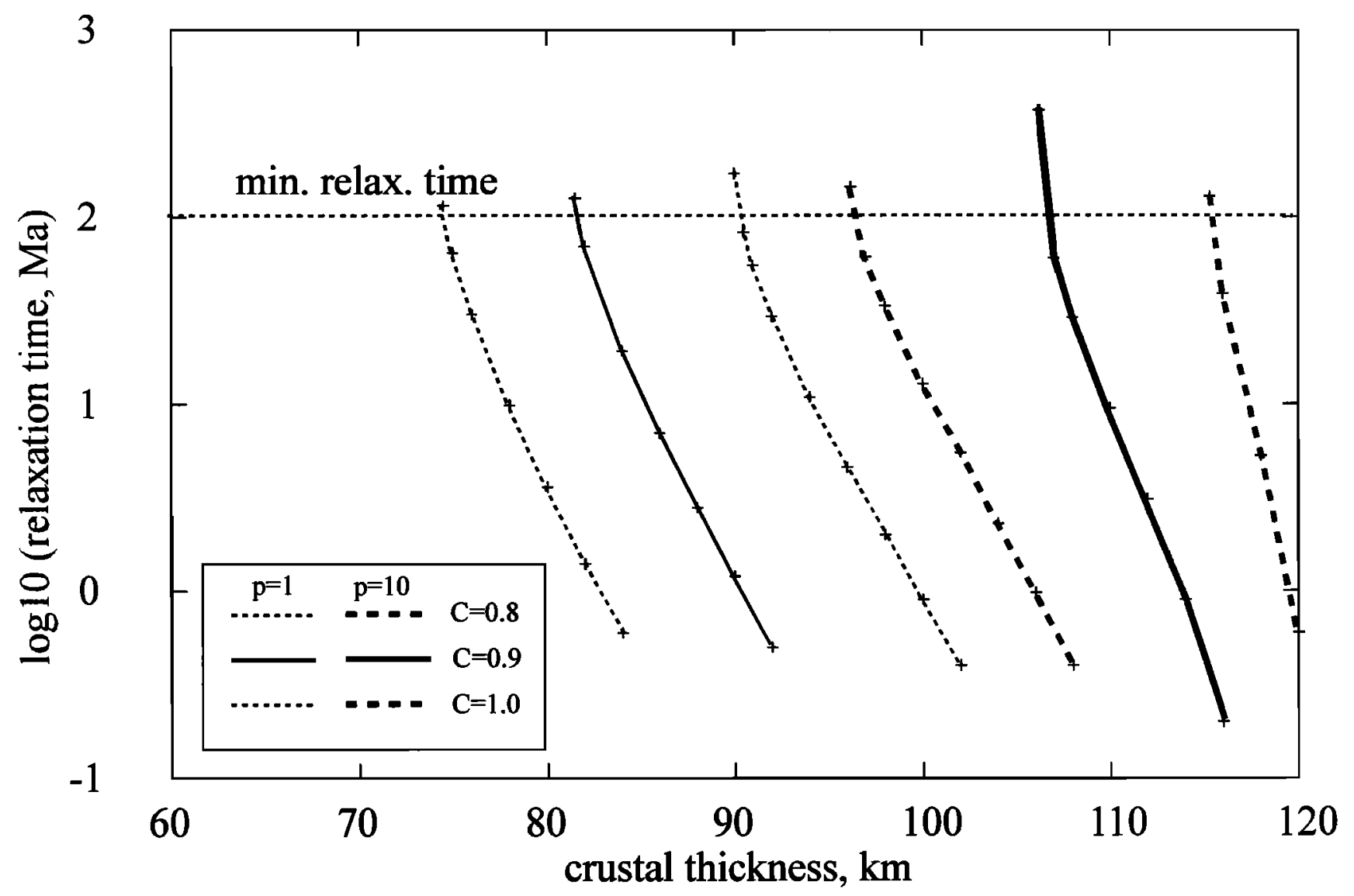

Figure 6. Relaxation time (see text) as a function of crustal thickness, $p$, and ('. Relaxation times greater than $\sim 100$ Myr indicate that the slope will not decay over the lifetime of the planet.

becomes comparable to the timescale over which the crustal temperatures decrease owing to radioactive decay. Thus crustal thickness contrasts that survive for greater than $\sim 100 \mathrm{Myr}$ will survive for the lifetime of the planet. Hence the $100 \mathrm{Myr}$ timescale can be used to define an approximate upper bound on crustal thicknesses compatible with the present-day unrelaxed topography. For typical terrestrial MORB concentrations $(p=4)$ the maximum likely mean crustal thicknesses are 99,88 , and $80 \mathrm{~km}$ for $(i=0.8,0.9$, and 1.0 , respectively (see Figure 6).

Because higher values of $\mu$ reduce $T_{b}$, greater crustal thicknesses are possible as $p$ mcreases. However, $p$ cannot increase beyond the point at. which all the radiogenic elements are in the crust. For a $110 \mathrm{~km}$ thick crust, $p \leq 11$. Hence, at crustal thicknesses of $\sim 100 \mathrm{~km}$ and $p=10$ the mantle has bern stripped of essentially all its radiogenic elements. Thus, for values of $C^{\prime}$ of 0.8 , (0.), and 1.0 the maximum likely mean crustal thickne'sses are 115. 107, and $97 \mathrm{~km}$, respectively. If appre(iable quantities of racliogenic elements remain in the mantle, these values would decrease. We report these extreme results for completeness only; in reality, it is very unlikely that one could have both a thick crust and a high value of $p$. For crust generated by single- stage melting, we expect the value of $p$ to anticorrelate with crustal thickness.

\subsection{Hellas Basin}

The main problem with modeling topographic relaxation of impact craters is knowing their initial shape. A conservative way of estimating maximum crustal thickness is to take the observed, prosent-dlay shape of the crater and investigate whethor this profile would have relaxed significantly over if (iy Thlis implucitly assumes that the crater was isostatically compensated before significant lateral flow took place: however, as discussed above, isostatic efmulibrum is gemerally reached berore lateral crustal thickness conl basts are smoothed out. A further problem is the cylindracal symmetry of 1.Je crater. In the following we used an axisymmetric version of (9).

The profile of Hellas is well described by a Gaussian of width $600 \mathrm{~km}$ and amplitude $8 \mathrm{~km}$ rising from a flat floor of radius $500 \mathrm{~km}$ (see Figure 7 ). Gravity data [Smuth et al., 1999b] show that Hellas is essentially isostatically compensated. If the compensation mechanism is Airy isostasy, the minimum average crustal thickness is $45-68 \mathrm{~km}$ for mantle densities of $3300-3400 \mathrm{~kg} \mathrm{~m}^{-3}$ and crustal densities of $2800-$ 

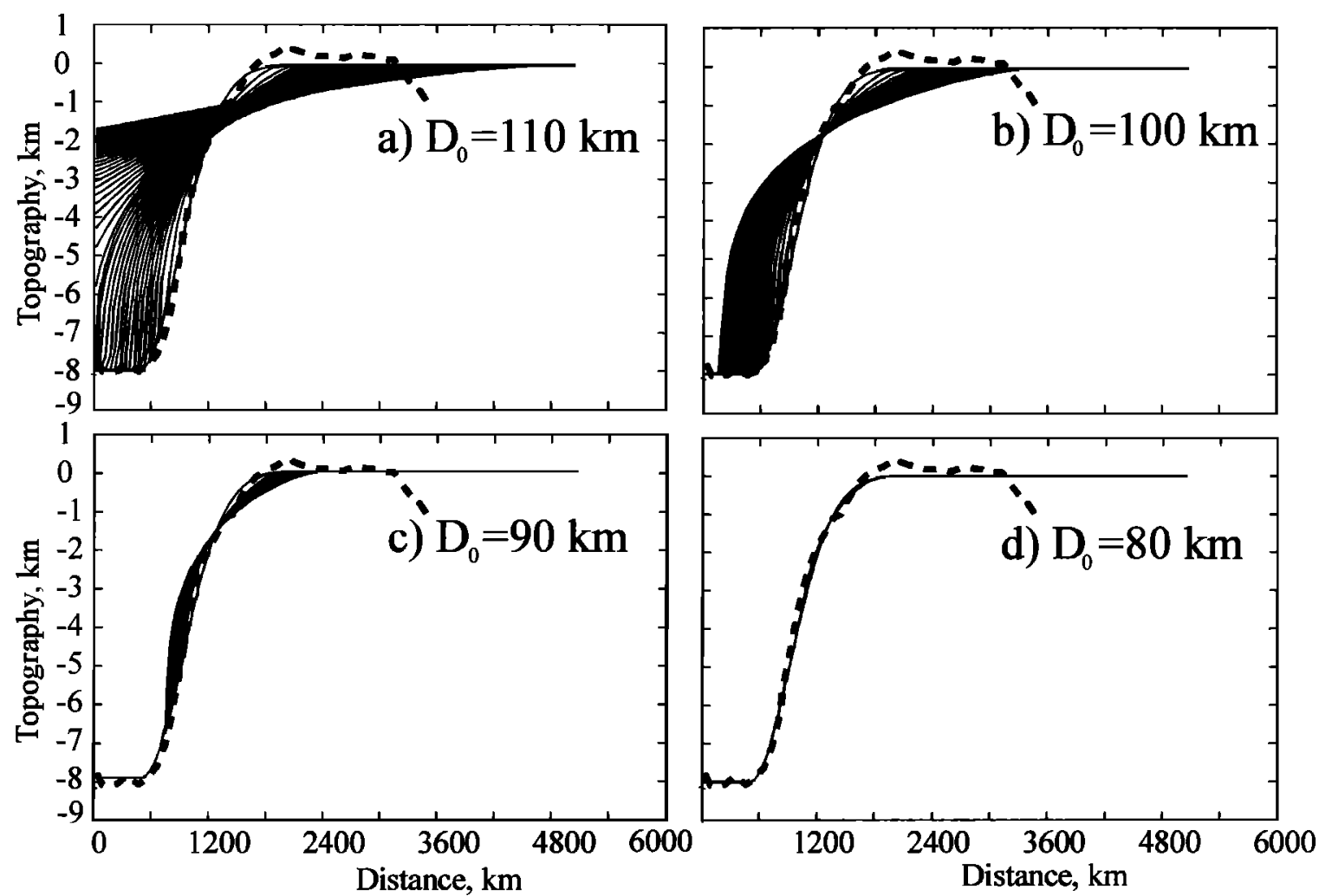

Figure 7. Evolution of Hellas topography with time. Solid lines show topographic evolution calculated as for Figure 5 except that an axially symmetric version of (9) is used and $D_{0}$ refers to the crustal thickness prior to the Hellas impact. Dashed line is radially averaged observed topograpliy.

$2900 \mathrm{~kg} \mathrm{~m}^{-3}$. Bills and Ferrart [1978] found a lower range mainly because they underestimated the depth of the basin. If the mechanism is Pratt compensation, the crustal thickness can be less than $45-68 \mathrm{~km}$ only if the density of the impacted crust exceeds the mantle density.

Figures $7 \mathrm{a}-7 \mathrm{~d}$ show the change in topographic profile over $4 \mathrm{Gyr}$ using the axisymmetric version of (9) and time-dependent $T_{b}$ for different crustal thicknesses. Here $D_{0}$ represents the crustal thickness prior to the excavation of Hellas. For $C=0.9$ and $p=4$, southern crustal thicknesses much greater than $90 \mathrm{~km}$ appear to be incompatible with the $\sim 4 \mathrm{Gyr}$ age of the Hellas basin For the same parameters a sinilar conclusion was reached from the crustal dichotomy.

\section{Discussion}

The above results are all consistent with an upper bound on the crustal thickness of the southern hemisphere of $\sim 125 \mathrm{~km}$ and a lower bound of $45 \mathrm{~km}$. The upper bound is a conservative estimate, based on low total radiogenic abundances $(C=0.8)$ and near-total extraction into the crust $(p=10)$. Using the previously calculated crustal thickness contrast across the hemispheric dichotomy, these bounds translate into a mean planetary crustal thickness of about $30-115 \mathrm{~km}$. For a case analogous to terrestrial MORBs, where $p=4$, an upper bound on the mean crustal thickness is $\sim 100 \mathrm{~km}$. This estimate is consistent with the result of Zuber et al. [2000].

The maximum crustal thickness estimate depends heavily on the total abundance of radiogenic elements and their distribution between crust and mantle. This distribution depends on the mechanism by which the crust was formed. If the Martian crust was formed by adiabatic upwelling of undepleted mantle [McKenzie and Bickle, 1988], $p \approx 4$ and will scale inversely with the melt fraction. For more complicated formation mechanisms there is no simple relationship between crustal thickness and radiogenic element concentration. Blachert-Toft et al. [1999] see evidence for multistage crustal formation, involving both large and small melt fractions, but argue that Mars is unlikely to possess analogues to terrestrial continents or lunar highlands. The uncertainty in likely crustal $p$ values is the largest source of uncertainty in our model.

It is unlikely that the average concentration of radiogenic elements in the crust has a value $p<4$, since such low concentrations probably require average melt fractions of around $25 \%$, seen only at terrestrial mid-ocean ridges on Earth. If $p$ is low, then the crustal thickness is also limited by the depth to the basalt solidus $(\sim 1500 \mathrm{~K})$. For a crustal thickness of $90 \mathrm{~km}$ the base of 
the crust would probably melt unless $p>8$ or $C<0.9$. Higher values of $p$ imply that most radiogenic elements have been extracted from the mantle. Such extraction would have a strong effect on the subsequent thermal history of the mantle. Early extraction of the majority of incompatible elements is supported by SNC geochemistry [Borg et al., 1997; Blichert-Toft et al., 1999].

The theoretical models predict a distinctive shape to the expected dichotomy boundary, were it once sharper than its current profile. Even allowing for uncertainties in rheology and short-wavelength irregularities, the observed profiles (Figure 3) show no obvious similarities to the predicted profiles (Figure 4). In particular, the theoretical profiles show higher curvature and slopes on the northern (low crustal thickness) side of the profile than on the southern (high crustal thickness) side. The absence of evidence for a relaxation profile must mean that to a good approximation, the observed profile is the outcome of the processes that made the dichotomy, and possibly degradational processes (erosion) not represented by our model. In particular, if relaxation did not occur at the relatively short wavelengths associated with the dichotomy, it cannot be responsible for the long-wavelength regional slope (see Figure 3 ). The regional slope in crustal thickness and the width of the topographic offset are significant features that demand explanation; the importance of the current work lies partly in excluding one possible explanation.

Throughout this work the effect of elastic support of topography has been ignored. Zhong [1997] shows that if the crust is elastic, the Moho topography will decay over the relaxation timescale $\tau_{2}$, whereas surface topography will be rigidly supported, leading to an eventual positive gravity anomaly. However, the effect of elastic support of topography appears to be minor in the case of both the crustal dichotomy and Hellas, since both these features are close to isostitic equilibrium.

It was assumed in the original calculations that the mantle heat flux is equal to the radiogenic heat production rate (minus a crustal component). On Earth the rate of heat loss is about twice the heat generation rate, probably because of the influence of plate tectonics and layered convection [Mckicnare and Richter, 1981]. Models of thermal evolution in single-layered planets convecting in the stagnant lid regime [Nimmo and Stevenson, 2000] show that during secular cooling, the mantle heat flux varies between about 1 and 1.2 times the radiogenic heat production rate, neglecting core solidification. Increasing the mantle heat flux above the assumed radiogenic value would reduce the permitted crustal thickness.

Mantle layering, in addition to changing the ratio of heat generation to heat loss, may also reduce the fraction of radiogenic elements extracted from the mantle. Retaining a higher proportion of radiogenic elements in the mantle reduces the maximum permitted crustal thickness (see section 4), so mantle layering, if present on Mars, is unlikely to change our conclusions.

Principally because of its short half-life, the decay of ${ }^{40} \mathrm{~K}$ accounts for $\sim 45 \%$ of radioactive heat production $4 \mathrm{Gyr}$ ago, whereas at the present day ${ }^{238} \mathrm{U}$ and Th are more important. The abundance of $\mathrm{K}$ in the Martian mantle is thus the most important factor in determining ancient heat fluxes. From SNC measurements, K/U ratios in Mars are thought to be a factor of 2 higher than terrestrial ratios [Wanke and Dreibus, 1988; Taylor, 1992]. Treiman et al. [1986] assumed a terrestrial K/U ratio, but Longhi et al. [1992] concluded that this assumption was less likely, as it required fractionation between different refractory lithophile elements. Wanke and Dreıbus [1988] assumed that the refractory lithophiles such as $\mathrm{U}$ and $\mathrm{Th}$ are present in the Martian mantle in chondritic (CI) abundances. The radiogenic abundances of Wanke and Dreabus [1988], Laul et al. [1986] and Treiman et al. [1986] produce mantle heat fluxes at $4 \mathrm{Ga}$ B.P. of 63,64 , and $48 \mathrm{~mW} \mathrm{~m}^{-2}$, respectively. The heat flux produced using $90 \%$ of the Sun and McDonough [1989] abundances (i.e., $C=0.9$ ) is $60 \mathrm{~mW} \mathrm{~m}^{-2}$.

A CI composition for Martian refractory lithophiles still seems to be the most reasonable assumption, though there is some evidence from oxygen isotope ratios [Sanloup et al., 1999] and moment of inertia clata [Bertka and Fei, 1998] that it may be too simple. Accordingly, our lower bound on total radiogenic abundances of $C=0.8$ is probably conservative. If, however, the Treiman et al. [1986] calculations are correct, $C=0.7$ and the maxinum crustal thickness estimates would increase by another $15 \mathrm{~km}$.

McKenzle and Brckle [1988] calculated the thickness of basaltic crust generated at mid-ocean ridges. Applying their method to Mars, a crustal thickness of $30 \mathrm{~km}$ can be produced by a Martian mantle potential temperature of $1350^{\circ} \mathrm{C}$. The thickness of melt generated is greater than that on Earth owing to the lower gravity. This temperature is compatible with models of Martian thermal evolution [e.g., Nımmo and s'tevenson, 2000]. Production of a $100 \mathrm{~km}$ thick basaltic crust. however, reyurres a potential temperature of $1600^{\circ} \mathrm{C}$. On the present-day Earth, such temperatures are thought to exist only at the centers of mantle plumes [e.g., Whate and Mchienzle, 1995].

A thick basaltic crust would make subduction difficult. A $200 \mathrm{~km}$ thick lithosphere would be $\sim 120 \mathrm{~kg} \mathrm{~m}^{-3}$ denser than the asthenosphere for an asthenospheric mantle temperature of $1600 \mathrm{~K}$, assuming a thermal expansivity of $4 \times 10^{-5} \mathrm{~K}^{-1}$. If the top $35 \mathrm{~km}$ were replaced by crust of density $2900 \mathrm{~kg} \mathrm{~m}^{-3}$, the lithosphere would become slightly buoyant. Thus the crustal thickness values derived in this study suggest that large-scale subduction of even the northern hemisphere is unlikely to have occurred. 


\section{Conclusions}

Topographic contrasts will be reduced by viscous flow in the lower crust at a rate depending on the viscosity structure of the crust. The viscosity structure depends on the abundance of radiogenic elements and the rheology of the crust. For likely rheologies and radiogenic abundances $C \geq 0.8$, Martian topography that formed 4 Gyr ago, such as the large impact basins and hemispheric dichotomy, can have survived only if the mean Martian crustal thıckness was $<115 \mathrm{~km}$. The absence of features characteristic of lower crustal flow in the crustal dichotomy profile suggests that such flow has not substantially modified the original situation.

The presence of large impact basins, such as Hellas, which are isostatically compensated, suggests that the crustal thickness in the southern hemisphere must exceed $40 \mathrm{~km}$. Given the uncertainties, improved bounds on crustal thickness are unlikely to be available until seismic data are obtained. A more accurate value will be important for future models of melt generation, radiogenic abundances, gravity, and magnetization.

Acknowledgments. We thank Norm Sleep and Shijie Zhong, whose comments greatly improved this manuscript. This research was funded by Magdalene College, Cambridge, and the California Institute of Technology.

\section{References}

Bandfield, J.L., V.E. Hamilton, and P.R. Christensen, A global view of Martian surface compositions from MGSTES. Scrence, 287, 1626-1630, 2000.

Bertka, C.M., and Y.W. Fei, Implications of Mars Pathfinder data for the accretion history of the terrestrial planets, Scuence, 281, 1838-1840, 1998.

Bills, B.G., and A.J. Ferrari, Mars topography, harmonics and geophysical implications, J. Geophys. Res., 83, 3497$3508,1978$.

Bindschadler, D.L., and E.M. Parmentier, Mantle flow tectonics: The influence of a ductile lower crust and implications for the formation of topographic uplands on Venus, J. Geophys. Res., 95, 21,329-21,344, 1990.

Bird, P., Lateral extrustion of lower crust from under high topography in the isostatic limit, J. Geophys. Res., 96, 10,275-10,286, 1991.

Blichert-Toft, J., J.D. Gleason, P. Telouk, and F. Albarede, The Lu-Hf isotope geochemistry of shergottites and the evolution of the Martian mantle-crust system, Earth Planet. Scı. Lett., 173, 25-39, 1999.

Borg, L.E., L.E. Nyquist, L.A. Taylor, H. Wiesmann, and C.-Y. Shih, Constraints on Martian differentiation processes from $\mathrm{Rb}-\mathrm{Sr}$ and $\mathrm{Sm}-\mathrm{Nd}$ isotopic analyses of the basaltic shergottite QUE94201, Geochim. Cosmochim. Acta, 61, 4915-4931, 1997.

Bott, M.H.P., Modeling local crustal isostasy caused by ductile flow in the lower crust, J. Geophys. Res., 104, 20,349$20,359,1999$.

Folkner, W. M., C. F. Yoder, D. N. Yualı. E. M. Standish, and R. A. Preston, Interior structure and seasonal mass redistribution of Mars from radio tracking of Mars Pathfindel. Scuence, 278. 1749-1752, 1997.

Frey, H., S.E. Sakinoto, and J. Roark, The MOLA topo- graphic signature at the crustal dichotomy boundary zone on Mars, Geophys. Res. Lett., 25, 4409-4412, 1998.

Greeley, R., and B. D. Schneid, Magma generation on MarsAmounts, rates and comparisons with Earth, Moon and Venus, Scrence, 254, 996-998, 1991.

Grimm, R.E., and S.C. Solomon, Viscous relaxation of impact crater relief on Venus: Constraints on crustal thickness and thermal gradient, J. Geophys. Res., 93, 11,911$11,929,1988$.

Hillgren, V.J., and H.J. Melosh, Crater relaxation on Ganymede-Implications for ice rheology, Geophys. Res. Lett., 16, 1339-1342, 1989.

Janle, P., Bouguer gravity profiles across the highlandlowland escarpment on Mars, Mcon Planets, 28, 55-67, 1983.

Kiefer, W.S., B.G. Bills, and R.S. Nerem, An inversion of gravity and topography for mantle and crustal structure on Mars, J. Geophys. Res., 101, 9239-9252, 1996.

Kruse, S., M. McNutt, J. Phipps-Morgan, and L. Royden, Lithospheric extension near Lake Mead, Nevada: A model for ductile flow in the lower crust, J. Geophys. Res., 96, 4435-4456, 1991.

Kusznur, N.J., and D.H. Matthews, Deep seismic reflections and the deformational mechanics of the continental lithosphere, J. Petrol., Special Lithosphere Issue, 64-87, 1988.

Laul, J.C., et al, Chemical systematics of the Shergotty meteorite and the composition of its parent body (Mars), Geochım. Cosmochim. Acta, 50, 909-926, 1986.

Longhi, J., E. Knittle, J.R. Holloway, and H. Wanke, The bulk composition, mineralogy and internal structure of Mars, in Mars, edited by H. H. Kieffer et al., pp. 184-208, Univ. Ariz. Press, Tucson, 1992.

Mackwell, S.J., M.E. Zimmerman, D.L. Kohlstedt, and D.S. Scherber, Experimental deformation of dry Columbia diabase: Implications for tectonics on Venus, in Rock $\mathrm{Me}$ chanics: Proceedings of the 35th U.S. Symposium, edited by J. J. K. Daemen and R. A. Schultz, pp. 207-214, A.A. Balkema. Brookfield, Vt., 1995.

McGill, G.E., and A.M. Dimitriou, Origin of the global dichotomy by crustal thinning in the late Noachian or early Hesperian, J. Geophys. Res., 95, 12,595-12,605, 1990.

McKenzie, D., and M.J. Bickle, The volume and composition of melt generated by extension of the lithosphere, $J$. Petrol., 29, 625-679, 1988.

McKenzie, D., and F. Richter, Parameterized convection in a layered region and the thermal history of the Earth, $J$. Geophys. Res., 86, 11,667-11,680, 1981 .

McKienzie, D., F. Nimmo, J.A. Jackson, P.B. Gans, and E.L. Miller. Characteristics and consequences of flow in the lower crust, J. Geophys. Res., 105, 11,029-11,046, 2000.

McSween, H.Y.. What we have learned about Mars from SNC meteorites. Meteoritics, 29, 757-779, 1994.

McSween, H.Y., et al., Chemical, multispectral, and textural constraints on the composition and origin of rocks at the Mars Pathfinder landing site, J. Geophys. Res., 104, 8679$8715,1999$.

Nakada, M., Convective coupling between ductile lower crust and upper mantle, and its tectonic implications, Geophys. J. Int., 118, 579-603, 1994.

Neumann, G.A., M.T. Zuber, D.E. Smith, and F.G. Lemoine, The lunar crust: Global structure and signature of major basins, J. Geophys. Res., 101, 16,841-16,863, 1996.

Nimmo, F., and D. Stevenson, Influence of early plate tectonics on the thermal evolution and magnetic field of Mars, J. Geophys. Res., 105, 11,969-11,979, 2000.

Norman, M.D., The composition and thickness of the 
crust of Mars estimated from rare earth elements and neodymium isotopic compositions of Martian meteorites, Meteoritıcs, 34, 439-449, 1999.

Ojakangas, G.W., and D.J. Stevenson, Polar wander of an ice shell on Europa, Icarus, 81, 242-270, 1989.

O'Nions, R.K., and D.P. McKenzie, Melting and continent generation, Earth Planet. Sci. Lett., 90, 449-456, 1988.

Phillips, R.J., The geophysical signature of the Martian crustal dichotomy, Eos Trans. $A G U, 69,389,1988$.

Sanloup, C., A. Jambon, and P. Gillet, A simple chondritic model of Mars, Phys. Earth. Planet. Inter., 112, 43-54, 1999 .

Schubert, G., S.C. Solomon, D.L. Turcotte, M.J. Drake, and N.H. Sleep, Origin and thermal evolution of Mars, in Mars, edited by H. H. Kieffer et al., pp. 147-183, Univ. Ariz. Press, Tucson, 1992.

Shelton, G., and J. Tullis, Experimental flow laws for crustal rocks, Eos Trans. $A G L^{\prime}, 62,396,1981$.

Sjogren, W.L., and R.N. Wimberley, Mars: Hellas Planitia gravity analysis. Icarus, 45, 331-338, 1981.

Smith, D.E., et al., The global topography of Mars and implications for suface evolution, Science, 284, 1495-1503, 1999 a.

Smith, D.E., et al., The gravity field of Mars: Results from Mars Global Surveyor, Science, 286, 94-97, 1999b.

Sohl, F., and T. Spohn, The interior structure of Mars: Implications from SNC meteorites, J. Geophys. Res., 102, 1613-1635, 1997.

Sun, S. S., and W. F. McDonough, Chemical and isotopic systematics of oceanic basalts: Implications for mantle composition and processes, Geol. Soc. Spec. Publ., 42, 313-345, 1989.

Tanaka, K.L., D.H. Scott, and R. Greeley, Global stratigraphy, in Mars, edited by H. H. Kieffer et al., pp. 345-382, Univ. Ariz. Press, Tucson, 1992.
Taylor, S.R., Solar System Evolution: A New Perspective, Cambridge Univ. Press, New York, 1992.

Taylor, S.R., and S.M. McLennan, The Continental Crust: Its Composition and Evolution, Blackwell Sci., Malden, Mass., 1985.

Thomas, P.J., and G. Schubert, Crater relaxation as a probe of Europa interior, J. Geophys. Res., 91, 453-459, 1986.

Treiman, A. H., M. J. Drake, M.-J. Janssens, R. Wolf, and M. Ebihara, Core formation in the Earth and shergottite parent body (SPB): Chemical evidence from basalts, Geochim. Cosmochim. Acta, 50, 1071-1091, 1986.

Turcotte, D.L., and G. Schubert, Geodynamics, 450 pp., John Wiley, New York, 1982.

Wanke, H., and G. Dreibus, Chemical composition and accretion history of terrestrial planets, Philos. Trans. $R$. Soc. London, Ser. A, 235, 545-557, 1988.

White, R.S., and D. McKenzie, Mantle plumes and flood basalts, J. Geophys. Res., 100, 17,543-17,585, 1995.

Zhong. S., Dynamics of crustal compensation and its influences on crustal isostasy, J. Geophys. Res., 102, 15,287$15,299,1997$.

Zuber, M.T., et al., Internal structure and early thermal evolution of Mars from Mars Global Surveyor topography and gravity, Science, 287, 1788-1793, 2000.

F. Nimmo and D. Stevenson, Division of Geological and Planetary Sciences, California Institute of Technology, 1200 East California Boulevard, Pasadena, CA 91125. (nimmo@igps.caltech.edu; djs@̋gs.caltech.edu)

(Received July 20, 2000; revised November 16, 2000; accepted November 29, 2000.) 